\title{
Research on the correct handling of mass incidents network public opinion
}

\author{
Zhang YunLing
}

Xi'an International University, Xi'an, 710077, China.

Keywords: college students; mass incidents; network public opinion; Countermeasures

\begin{abstract}
College Students' active thinking, and is in a critical period of the formation of outlook on life, world outlook, ideology is not very mature, facing the problem of network public opinion will blindly follow the trend, the formation of group events. In this paper, existing in the disposal of the group event of network public opinion problems and countermeasures were studied. At the same time, summed up the countermeasures to improve the correct handling of mass incidents of network public opinion, the public information in a timely manner, strict supervision of network public opinion, expand the way to communicate with the public, the establishment of public opinion special handling mechanism and improve the network public opinion disposal laws and regulations.
\end{abstract}

\section{Introduction}

Network public opinion can reflect the degree of social stability, public opinion and the change is reflected people's attitudes and opinions. With the development of Internet technology, more and more people to participate in the network space. The network has gradually become a new way of public expression of self thinking, touched the network platform because of its anonymity the nature, rapidly becoming the platform of choice for public communication, network public opinion as the platform continues to grow, causing collateral greater impact on social stability and handling group incidents. If the exposure a group events in the network, the network Everfount views will lead to a nationwide public opinion. If the improper disposal will make some local, accidental, immediately turn into public topic. This attracted national attention will bring more difficulties to the maintenance of social stability, will also have a greater impact on social stability.

\section{Group event concept}

In China, the "mass incidents" is often referred to as the unexpected events of the group, the group security incidents and violence. In foreign countries, scholars of "mass incidents" described as "collective behavior" or "collective behavior". According to sociologist Popenoc definition of group events, group events refers to the relatively spontaneous, unpredictable, no organization and stability under the condition of a common effect or a stimulus event [7]. group events in various forms, including demonstrations, riots, looting. Although the form of group events are different in some aspects, but they but on the other side, the social control mechanism is weak, and the expectations of the people who participate in the group events are not clear.

\section{The concept of network public opinion}

Network public opinion refers to in certain social space, through the network around the intermediary social events, the change and development of social and political attitudes held by the people of public and social management, beliefs and values of [8]. it is more people on each kind of social phenomenon, the problem of expression of faith, attitude the sum of opinions and emotions, and so on. The performance of network public opinion formed rapidly, huge impact on society. With the rapid development of the Internet in the global scope, the network media has been recognized as the following newspapers, radio, television after the "fourth media", the network has become the main carrier of public opinion. 


\section{Improve the correct handling of mass incidents network public opinion Countermeasures}

As the government network public opinion events group governance body, it is necessary to have a responsibility, in the group after the incident, take proper measures against the event of network public opinion in our country. The network group has a lot of popularity in the background, once the government of mass incidents of network public opinion and improper disposal will be four rumours prompted in the real world of mass incidents deterioration caused by unpredictable losses. Therefore, the Countermeasures of government dealing with group incidents of network public opinion research is necessary.

\section{Timely disclosure of information}

When the group after the incident, the government need to be released through the media about the group event information, to solve public doubts. Once the government withheld information or public information is not timely, it will give the network rumors, negative public opinion has a development opportunity, the opportunity to sway public opinion. When the network public opinion positive leading lose the status, the government issued the information in the rumor, it is difficult to play a very good guide effect. According to the survey data show that $83.7 \%$ of respondents in the news that some network hot events, will try to further understand this hot events by other means; $49 \%$ of the respondents in the self Don't understand events, the views of others will affect their thinking. This indicates that the government is not timely public information, citizens can easily be rumors misleading. But the government public information in a timely manner, it is necessary to pay attention to two points, namely the time of mass incidents were reported, truthfully reported.

\section{The situation of mass incidents in real time is reported.}

The group events from creation to extinction in the process will experience different stages, and the characteristics of each stage is not the same, so we must conduct real-time tracking of mass incidents, once found immediately change, release of information to the public. To avoid a reality in the world of group events has changed. The government, in the virtual world of information update is not the phenomenon.

\section{Truthfully report mass incidents}

Truthfully report the group events is to enhance the transparency of information disclosure. Truthfully report the group events is government officials with the truth, do not add in group events report personal picture. The author believes that the report is a very important part of the public information in a timely manner. Not only causes the various versions of the network reported that will make the public questioned the government's report, reducing the credibility of the government, is not conducive to the solution of the network public opinion event group.

\section{Strict supervision of the network public opinion}

The implementation of supervision of public opinion on the network, especially in network public opinion and network public opinion public opinion diffusion stage of germination stage supervision network, can help the government to find the demands of stakeholders in a timely manner, people have an ulterior motive to distort the facts made public after the misguided rumors and inaccurate information to express their views caused by the negative network public opinion, the the government knows what to do in the key stage of the disposal of network public opinion, so as to control the dominance of network public opinion, timely response, and effectively guide the network public opinion, and even have the opportunity to strangle the network public opinion in the bud stage. It is the so-called enemy, know yourself. I believe that strict Supervision of the network public opinion of the specific measures are mainly to report the event of the main personnel to implement the real name registration strategy and the establishment of network public opinion 
detection room.

\section{To report the incident to the main personnel to implement the real name registration strategy}

Because the network is anonymous, which leads to some of the media and personal reports on mass incidents, impunity was reported to group events comments, regardless of the accuracy of reported information. Take the real name registration strategy of key personnel reports, can be in a certain extent to solve the network features is anonymous. At the same time, when the reported problem, can timely find the person responsible. This prompted the media and personal reports in the not so random. In the Wenchuan earthquake, the government reported on the main event staff to take the real name registration strategy, and play a good effect.

\section{The establishment of network public opinion monitoring room}

In recent years, the network of public opinion to discuss the theme of more and more widely, the government is difficult to grasp the network public opinion the occurrence time and the direction of development. There are some universities for this problem to do related research. The Beijing Jiaotong University research center of security was established in 2009; after 2009, the Fudan University and the Shanghai Jiao Tong University and other famous universities have established research institutions. The government can learn from the experience of the colleges and universities as well as research results, a complete set of network public opinion monitoring system, establish the supervision of network public opinion own testing room, interested in the public sensitive topic and topic implementation .

\section{Ways to expand and communicate with the public}

In the event of network public opinion groups, the government should do is not only timely information about public events, guarantee the transparency of information disclosure, ways should also pay attention to information. If the way the government release information, and the way of information publicity is not in a discourse on the platform, even if the government in the group after the incident, the first time to release information, but because of the public discourse platform is different and can not keep abreast of events. This also is not the government discloses information in a timely manner. Therefore, the government needs on their official website, the traditional media published information at the same time, but also pay attention to in instant messaging, on Tan and the portal to release information.

\section{Release information via instant messaging}

Instant communication mainly refers to the QQ, WeChat and other exchanges, the questionnaire data show that up to $61.2 \%$ of the respondents first contact network public opinion on instant messaging. This shows that although there is every kind of network communication platform, but the public through instant messaging for maximum probability of network exchange. At present our country all levels of government his official website, but do not have their own official QQ and official WeChat. The government should register the official QQ and official WeChat's own, able to timely release of information through instant messaging in the group after the incident, the public and the way to ensure their information exchange in a discourse platform .

\section{Through the forum, portal release information}

Survey data show that $10.2 \%$ of the respondents in the forum for the first time to understand the network hot events. Although the public portal through the forum, portal to know the number of mass incidents are not many, but the government can not be ignored by the forum and portal release information. 


\section{Construction of specialized network public opinion management agencies}

Specialize in, can be unruffled. The government has constructed the network public opinion management specialized institutions, rather than the formation of networks of public opinion ad hoc working group, is likely to deal with the network public opinion in every group events. Therefore, the government wants to improve the network public opinion work, you need to have the network public opinion management mechanism special. And the composition of personnel management mechanism of network public opinion should have these characteristics: vision, strategic vision and good planning, strong ability of organization and command; familiar with the network, have a high political and professional quality; followed by the development of Internet technology, has a strong sense of innovation and technology research Familiar with network capacity; review of work, good use of "network language"; keenly capture public opinion, public opinion analysis judged accurately, fast and high quality writing network public opinion submitted. These people can train themselves, can also be introduced from the University.

\section{Improve the network public opinion disposal laws and regulations}

Based on advocating freedom of speech and is supported by a complete legal system. However, at present, China's laws and regulations for publicity on the Internet is not perfect, even in some is still in the blank. The legal system of the relevant government departments set for network supervision is not perfect, resulting in network politics no laws can be the reference, and to promote its effective implementation. Because of this, local government departments should construct a relatively complete network public opinion management system, all aspects of Internet coverage management. Strengthen the network legislation to make up for the defects of the existing laws and regulations, to timely modify, develop a A complete law, in order to promote the management of the network public opinion can have guidelines to follow, have legal basis. According to the actual situation of the contents of the legislation need to be arranged, make clear responsibility, reward. Confirm the relevant users and the main responsibility. The legal environment of network public opinion can be sustained and healthy development of the Internet public opinion specification to provide legal support, scientific development, make it in all aspects of social life and play a positive role.

To establish the perfect laws and regulations, can produce the deterrent effect of the public and government officials. When someone is in the network free to comment, spread rumors and government officials of public opinion on the network and improper disposal can be based on the relevant laws and regulations, make severe punishment for these people, so that the public can not spread rumors, government officials can not ignore the various stages of the network public opinion disposal. The maintenance of the network environment harmony, social stability and development.

\section{Conclusions}

Through the case analysis of the government's handling of mass incidents of network public opinion, and combined with the questionnaire analysis, the government in dealing with the problem of mass incidents network public opinion, and explore the corresponding countermeasures.

\section{References}

[1] Liu Yi. Research on network public opinion survey [M]. Tianjin: Tianjin people's publishing house, 2006,10-20.

[2] Liu Jianming. The principle of social public opinion [M]. Beijing: China Press, 2002,5-15.

[3] Chen Tan. The network public opinion of group events and its propagation logic [J]. theory, 2011 (7), 4-7.

[4] Yan Yan. Study on the network public opinion in group events [M]. Beijing: Xinhua Publishing 
House, 2013,20-25.

[5] Shi Cuixian, Yan Liping, Jin Lan. The government how to deal with the network public opinion research talent crisis [J]., 2011 (6), 15-30.

[6] Miao Zhuang. Group events of the network public opinion guide [J]. youth reporter, 2010 (5), 18.

[7] Li Qiongyao. Current situation and guidance of network public opinion. Journal of Hunan Administration College, 2006 (2), 6-28.

[8] Jiang Sheng hong. The status quo of China's Internet public opinion and its guide [J]. Guangxi social science, 2009 (L), 26. 